\title{
Prevalence of depression in residents of gerontology centre in Sarajevo
}

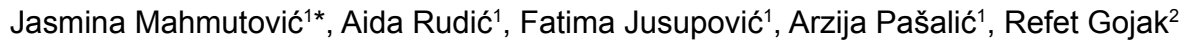 \\ ${ }^{1}$ Faculty of Health Studies, University of Sarajevo, Bolnička 25, Sarajevo, Bosnia and Herzegovina. ${ }^{2}$ Department of Infectious \\ diseases, Clinical Center of University of Sarajevo, Bolnička 25, Sarajevo, Bosnia and Herzegovina
}

\begin{abstract}
Introduction: Depressive disorder, as a major problem of public health, takes high fourth place in its prevalence in general population, and is considered to be the second most frequent health problem of female population. Depression is the most frequent mental problem of persons in their third age of life. The aim of this study is to evaluate prevalence of depression and establish the ratio between the current number of diagnosed and of unrecognised depression among the residents of Gerontology Centre in Sarajevo.

Methods: This is a cross-sectional, descriptive, and analytical study undertaken throughout May and June 2011 on the sample of 150 residents of "The Gerontology Centre" in Sarajevo that were above 65 years of age. The following instruments were used for the research: the Geriatric Depression Scale (GDS), modified questionnaire consisting of two parts (general data and data related to health state), and the medical records of the residents. For statistic analysis of data was used the SPSS program for Windows.

Results: According to GDS, prevalence of depression was $65.3 \%$, out of which mild depression occurred in $46.7 \%$ cases and severe depression in $18.7 \%$. The prevalence of verified (diagnosed) depression was 11.3 per cents.

Conclusions: According to the GD scale, unrecognised depressions seem to be almost six times more frequent $(65.3: 11 \%)$ than is the case with depressions diagnosed in medical records of the protégées of the Gerontology Centre in Sarajevo. Timely recognition of depression and its treating in institutions for protection of health of persons in third age of life can substantially improve the quality of life of these patients.
\end{abstract}

(C) 2012 All rights reserved

Keywords: persons of third age, depression, Geriatric Depression Scale - GDS

\section{Introduction}

Ageing is universal, natural process that involves members of all the biological species that are alive. The ageing becomes one of the main topics in many sciences ranging from biological through social to psychological ones. The main reason for increased exploring of the subject has to do with swift increase of percentage of elderly people in general population of the developed countries (1). Continuous growth of elderly population is evident in our country, too (2). Each community is burdened with increased needs of elderly persons, mainly those concerning the health

\footnotetext{
* Corresponding author: Ms. Jasmina Mahmutović,

Faculty of Health Studies, University of Sarajevo,

Bolnička 25, Sarajevo, Bosnia and Herzegovina

Telephone: +387 33569 825;

E-mail:jmahmutovic@yahoo.com
}

Submitted 13. March 2012/Accepted 16. April 2012 and social protection, and this is especially case with poorer countries as is ours (3). The entire world is tending to indulge all the relevant factors - health services, scientific researches, social services, education, etc. - in synchronised efforts to create environment in which the extended life span is as good as possible, meaningful, and dignified; it is the only way of life that is worthwhile (4). According to the World Health Organisation, the main threats to the health of elderly people are: dementia, depression and suicide, as well as the cancer, cardiovascular illnesses, osteoporosis, incontinency, and injures (5). Depressive disorder, as major problem of public health, takes the high fourth place in its prevalence in general public, and is the second most frequent health problem of female population. WHO predicts that by the year of 2020 the depression would became the second health problem of the world 
and the leading health problem of the women (6). Regardless of the fact that the depression seems to be less common in later stages of life (1-3\%) than is the case with middle aged persons (6$8 \%)$, the depression still represents the most frequent mental disorder among the elderly persons (7). The depression affects the quality of life of elderly persons in many negative ways, such as their productivity, relations with other persons, but also influences somatic illnesses, especially those characteristic for the third age of life (1). The researches indicate that $15 \%$ of depressive patients commit suicide; more frequently men of older age. Timely recognition and adequate medical treatment of depression in the institutions for care of persons in third age of life, along with therapies available today, may substantially improve the life of these patients. Patients suffering from depression demand multidisciplinary approach to the treatment. Its early recognition is very important, as well as the efficient and sufficiently long treatment to avoid consequences and chronic outcome of the illness. Majority of countries strive to gradually introduce new, comprehensive types of non-institutional care of persons in third age that are oriented towards the elderly person in question and his/her family (3). The principal aim of this study is to evaluate prevalence of depression and establish the ratio between the current number of diagnosed and unrecognised depression among the residents of Gerontology Centre in Sarajevo.

\section{Methods}

The research was undertaken throughout May and June 2011 among the residents of C.P.I. "Gerontology Centre" in Sarajevo. The research included randomly selected 150 protégées over 65 years of age, who voluntarily consented to be part of the research. The criteria for inclusion of examinees into the research was that they are residents of Gerontology Centre in Sarajevo, that they are over 65 years of age, and that they are psychophysically capable to answer the questionnaire. The criteria for exclusion of residents of Gerontology Centre in Sarajevo from the examination: they were under 65 years of age or they were not psycho-physically capable to answer the questionnaire. This is a descriptive and analytical research of cross-sectional study. The instrument used for this research was the Geriatric Depression Scale (GDS), consisting of 30 Yes-No questions recommended by both the British Society of Gerontology and the Royal College of Physicians (8). Legend: 0-9 answers: no depression; 1019: mild depression; 20-30: severe depression. The survey covered modified questionnaire consisting of 17 questions seeking general information as well as the data on health condition. Secondary source of data: medical records of the residents of Gerontology Centre in Sarajevo were used for verification of certain data. For statistical analysis of data was used the SPSS program for Windows (Version 13.0, SPSSINC, Chicago, Illinois, SAD) and Microsoft Excell (Version 11, Microsoft Corporation, Redmond, WA, SAD). Descriptive statistical analysis were used to present demographic data. Chi Square test was used for analyse nominal and ordinal variables.

\section{Results}

This was a cross-sectional study on unrecognised depression among residents of Gerontology Centre in Sarajevo. The sample covered 150 examinees of both genders over 65 years of age. Out of the total number, $60 \%$ (90) were women, while the rest of samples were men, $40 \%$ (60), as seen on the Figure 1. The age of examinees varied from 65 to 105 years, where the average value of years was $\mathrm{Me}=80$ years. The interquartille range (Q1-Q3) was between 75 and 84 years of age.

The Figure 2 shows the educational structure of examined sample, clearly indicating that the big-

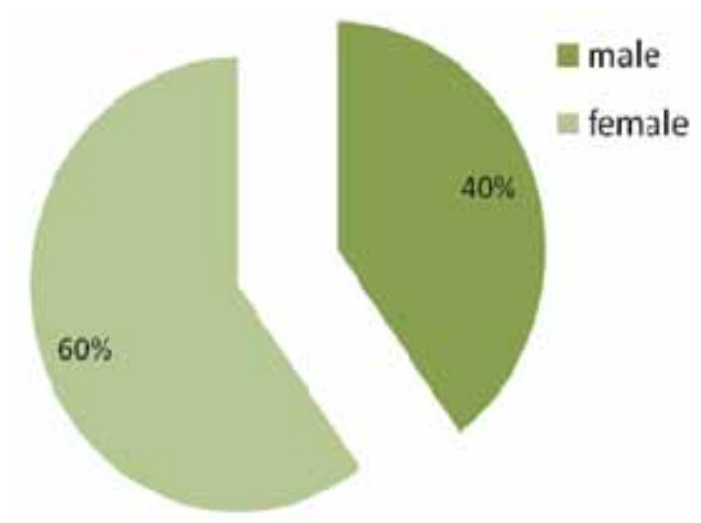

FIGURE 1. Gender structure of samples 


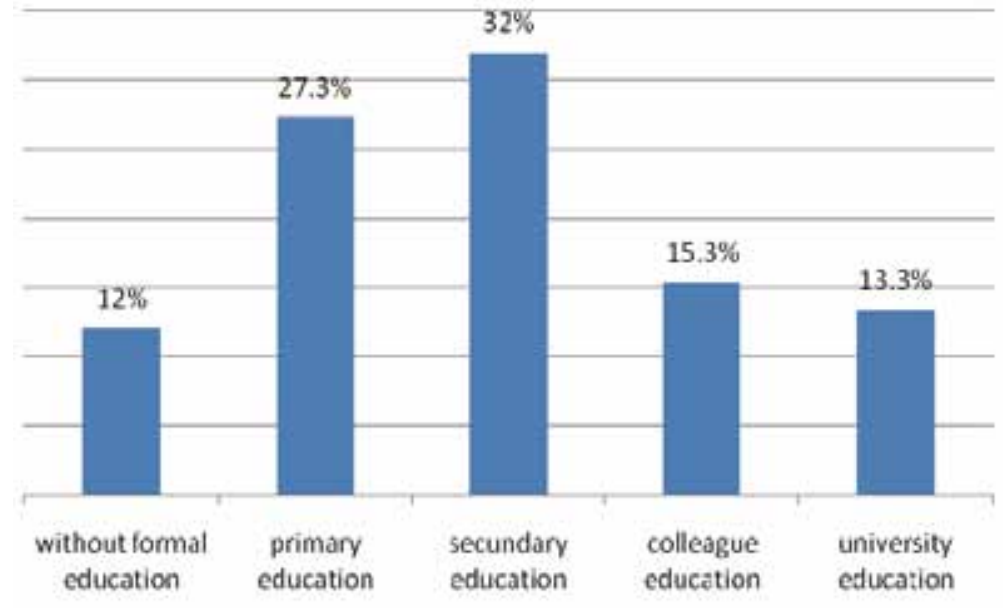

FIGURE 2. Percentual representation per level of education shown on the Figure 4. Table 1 presents the geriatric scale of depression where the examinees who got scores on the scale equal or less than 9 had no signs of depression, examinees in category from 10 to 19 scores had mild depression, and those with score from 20 to 30 suffered from severe depression. Out of the total sample measured by GDS, $34.7 \%$ (52) persons had no signs of depression, $46.7 \%$ examinees (70) had mild

gest number of examinees (32\%) was of secondary education, and $27.3 \%$ of examinees had primary education. Slightly less percentage was of those with colleague (15.3\%) and university degree (13.3\%). The total sample had the least percentage of examinees without formal education (12\%). When considered marital status of the examinees, analysis of Figure 3 clearly shows that the biggest percentage of examinees, 69\% (103), involves the category of widowed persons. The results on the rest of the groups of examinees were tight: (17) $11 \%$ - divorced, (16) 11\% - married and (14) $9 \%$ - single. By making insight into the medical records of the examinees, we had verified diagnoses of depression of 17 examinees (11\%), while the remaining number of 133 (89\%) residents of Gerontology Centre had no records on such diagnose, as

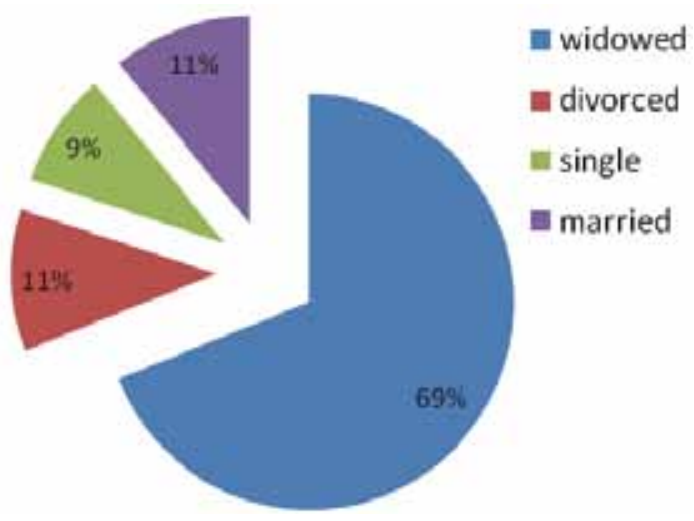

FIGURE 3. Marital status of examinees presence of depression, and $18.7 \%$ examinees (28) were in the scale of severe depression. The depressiveness of examinees was measured by Geriatric scale of depression and varied from 1 to 27 with average value of $\mathrm{Me}=13$, and interquartille range from 7 to 18 . 133 examinees had no registries on diagnosed depression in their medical records. Out of this number, the GD scale showed mild depression in 62, and severe depression in 22 cases. 17 examinees had in their medical records registries on confirmed diagnose of depression. Out of this number only three examinees were not depressive, eight persons had mild depression, and six of them suffered from severe depression, which means that we managed to recognise through the GD scale 14 examinees as being mildly or severely depressive.

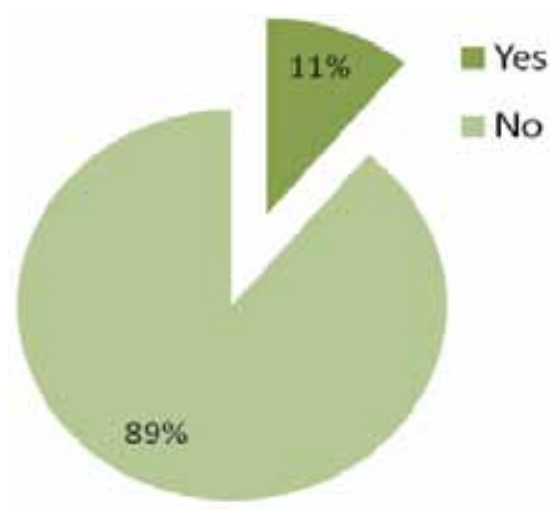

FIGURE 4. Prevalence of diagnosed depression 
TABLE 1. Geriatric scale of depression evidenced on examinees

\begin{tabular}{lcc}
\hline Categories of GD Scale & Number & Percentage \\
\hline $\begin{array}{l}\text { No depression } \\
<=9,00\end{array}$ & 52 & 34.7 \\
$\begin{array}{l}\text { Mild depression } \\
10,00-19,00\end{array}$ & 70 & 46.7 \\
$\begin{array}{l}\text { Severe depression } \\
20,00-30,00\end{array}$ & 28 & 18.7 \\
\hline Total & 150 & 100,0 \\
\hline
\end{tabular}

TABLE 2. Rate of verified diagnose of depression and unknown depression according to GDS

\begin{tabular}{lcccc}
\multirow{2}{*}{$\begin{array}{l}\text { Diagnosed } \\
\text { depression }\end{array}$} & \multicolumn{3}{c}{ GDS categories of depression } & \multirow{2}{*}{ Total } \\
\cline { 2 - 4 } & $<=9,00$ & $10,00-19,00$ & $20,00-30,00$ & \\
\hline Without & 49 & 62 & 22 & 133 \\
With & 3 & 8 & 6 & 17 \\
Total & 52 & 70 & 28 & 150 \\
\hline
\end{tabular}

Chi-squared test of independence showed that the connection between diagnose of depression and geriatric scale of depression is statistically significant, $\mathrm{p}=0.039$. $\mathrm{RR}$ - risk ratio $=2.54$

The examinees from the group with depression, according to GDS, have 2.5 times bigger risk of having diagnose on depression then those in group without depression according to GDS. OR - odds ratio $=2.72$

Odds ratio is approximating to $\mathrm{RR}$. Odds on having the diagnose of depression in the group "With depression according to GSD" is 2.7 times bigger than in group "Without depression according to GSD".

\section{Discusion}

The latest data indicate high prevalence of depression in institutions providing long-term protection and care (9). Presence of depression among residents of Gerontology Centre in Sarajevo was checked by using simple screening instrument - Geriatric Depression Scale (GDS). Depressiveness of examinees that is defined by the GD scale does not necessarily mean diagnosed depression, but is a warning sign that the person has or may have a serious problem, without be- ing aware of it. Either mild or severe depression defined by the GD scale indicates the need for engaging entire team of experts aimed at prevention of major development of depression or provision of adequate treatment, when needed. Early recognition and treatment of depression of persons in the third age of life considerably improves the quality of life of both the elderly and those who take care of them (10). Our research had shown very high prevalence of depression occurring with residents of Geriatric Centre in Sarajevo. According to the received results, $46.7 \%$ examinees suffer with mild, and $18.7 \%$ severe form of depression, which covers $65.3 \%$ of total number of depressive protégées. By analysing our sample, we can see that: the gender structure was in favour of women, which is demographic characteristic of industrialised countries; majority of examinees had completed secondary education; and, the largest percentage of them are in status of widowed persons. When compared to researches from 2011 when Huang and associates conducted among elderly people living in nine nursing homes of Great Britain, we see that the data on their depression prevalence was $32.3 \%$ (11), and, as such, is two times lesser than ours (65.3\%). Statistical data on prevalence of depression among residents of nursing homes in USA amounting to $43 \%$ also show lesser prevalence in depression than is the case with us $(65.3 \%)$ (12). In 2003, Jongenelis and associates from Netherlands had gathered 36 different Dutch studies on prevalence in depression in nursing homes and found that, in average, 43.9 per cents of examinees had presence of depressive symptoms (13). The research conducted in Australian nursing homes back in 2008 showed the information that $41.1 \%$ examinees were depressive according to the GD scale (14). Somewhat bigger frequency of depression in comparison to the above mentioned research, but also lesser than in our case $(65.3 \%)$, was shown in the 2011 research on elderly people in New Jersey that was conducted in eight nursing homes from 1999 to 2007 by Gaboda and associates (51.8\%) (15). Throughout the year of 2010, Aribi and associates had performed analytic and descriptive study in a nursing home in Tunisia establishing that the 
prevalence of depression there was $51.4 \%$ (16). Very similar data on prevalence in depression (57.7\%) (17) were got in 2007 by Chahine and associates who conducted the pilot study among residents of nursing homes in Lebanon. Cross-cut study conducted in China in 2011 revealed prevalence of depression in $27 \%$ of elderly persons of urban community (18). Its comparison to previous researches on the subject proves that the prevalence of depression among elderly persons in China is constantly growing. In 2005, by using the GD scale on elderly persons living in own houses situated in urban environment of Selangor, Malaysia, Sherina and associates got the impressive result of $6.3 \%$ (19), which is incomparably less than in all of the listed researches. A research conducted in our country on the DG scale depressiveness of persons over 65 of age that were treated in ambulances for primary health protection. This research resembled to ours in sense that the sample mainly consisted of women, though the average age was $73,2 \pm 5,15$ years, while in our research the age of examinees varied from 65 to 105 years, with average value of (median) $\mathrm{Me}=80$ years. Their research showed that the depressiveness was present in 55\% examinees (20), which do not show considerable difference in percentage when compared to our examinees $(65.3 \%)$. In Serbia, the research conducted throughout the year of 2010 in the Cuprija Medical Centre among persons of third age showed the prevalence of depression in $55 \%$ (21), which is identical to the depression prevalence results got in a $\mathrm{BiH}$ research on elderly persons treated in ambulances for primary health protection (55\%). Prevalence of depression (55\%) is somewhat lesser then in our research $(65.3 \%)$, but one has to consider the fact that these two researches were conducted among elderly population living in their houses.

\section{Conclusions}

Prevalence of depression among residents of Gerontology Centre in Sarajevo was determined by GD scale and reached figures of $65.3 \%$, out of which mild depression was registered in $46.7 \%$ cases and severe depression in $18.7 \%$ cases. The prevalence of verified (diagnosed) depression was $11 \%$. Unrecognised depression by GD scale was almost six times more frequent (65.3:11.3\%) than it was the case with diagnosed depression in medical records of residents of Gerontology Centre in Sarajevo. The connection between the diagnosed depression and geriatric scale of depression is statistically significant, $\mathrm{p}=0.039$. It is necessary to draft a protocol on prevention of manifested depression in persons of third age of life that are settled in institutions for providing long-term health care, and to define preventive programmes of this disease for persons of third age living in house conditions.

\section{References}

(1) Brajković L. Indicators of satisfaction with life in third stage of life. [Ph.D. Dissertation] Zagreb: Medical School of University in Zagreb.2010.

(2) Salihović H, Tanović-Mikulec E, Dračić, S. Aging of the population of the Sarajevo Canton as a consequence of unfavourable demographic trends. In: $4^{\text {th }}$ Days of Social Medicine - Public Health: proceedings. Travnik: Institute of Public Health of Srednje-bosanski Canton.2007.12 p

(3) Despot Lučanin J., Mojsović Z. Nursing Care on Elderly Persons in Community. In: Mojsović Z. et al. Nursing in Community. Zagreb: The Health Polytechnic of Zagreb,
2006. p.465-533.

(4) Salihović H. Aging - problems of growing old and their prevention. Sarajevo: Avicena, 2001.p. 11-141.

(5) WHO: Health 21 - Framework policy "European Health for All" of the World Health Organisation. Translation no. 45. The BiH Bureau for Health Protection, 2000;p.33-36.

(6) Murray CJL, Lopez AD. Alternative projections of mortality and disability by cause 1990-2020. Global Burden of Disease Study. Lancet. 1997; 349:1498-1504.

(7) Novović, Z.Structure of Clinical and Aging Depressiveness: Similarities and Differences. Psychology. 2006; 39(4): 425-437

(8) Gottfries CG, Karlsson I. Depres- sion in Later Life. Oxford: OCC Ltd;1997.32 p

(9) Gavranović M. Geriatry. Sarajevo: School of Health Sciences of the Sarajevo University; 2007. p.146-8.

(10) Gallo JJ, Gonzales J. Depression and other mood disorders. In: Adelman AM, Daly MP, Weiss BD eds. 20 common problems in geriatric. New York: McGraw Hill, 2001.p. 205-21.

(11) Huang Y, Carpenter I. Identifying elderly depression using the Depression Rate Scale as part of comprehensive standardised care assessment und nursing homes. Aging Ment.Health.2011; 15(8):10451051

(12) Depression Screening and Treat- 
ment. A Systems Approach to Quality Improvement in LongTermCare.Masspro.Available from: http://www.masspro.org/NH/ DEPR/docs/tools/DepressionWrkbk07.pdf//

(13) Jongelines K, Pot AM, Eisses AM, Beekman AT, Kluiter H,van Tilbugr W,et al.Depression among older nursing home patients. A review. Tijdschr Gerontol Geriatr. 2003;34(2):52-9

(14) Snowdon J, Fleming R. Recognising depression in residential facilities: an Australian challenge. Int J Geriatr Psychiatry. 2008;23(3):295-300

(15) Gaboda D, Lucas J, Siegel M, Kalay E, Crystal S. No longer undertreated? Depression diagnosis and antidepressant therapy long-stay nursing residents,1999 to 2007.J Am Geriatr Soc. 2011;59(4):673-80

(16) Aribi L, Elleuch E, Trabelsi S, Aloulou J, Maalej I, Amami O. Evaluation of depression in elderly people living in nursing homes: a study involving 35 people. Tunis Med. 2010; 88(10):710-3

(17) Chahine L.M, Bijlsma A, Hospers A.P.N., Chemali Z. Dementia and depression among nursing home residents in Lebanon: a pilot study. Int J Geriatr Psychiatry 2007;22(4).283-5

(18) Yunming L, Changseng C, Haibo T, Wenjun C, Shanhong F, Yan M, et al. Prevalence and risk factors for depression in older people in Xi'an China: a community-based study. Int J Geriatr Psychiatry 2011;
27(1):31-9

(19) Sherina M, Sidik RL, Aini M, M Norhidayati $H$. The prevalence of depression among elderly in an urban area of Selangor, Malaysia. The international Medical Journal. 2005; 4(2):57-63

(20) Čampara-Tirić M, Đelilović-Vranić J, Hrustić M, Jakubović B, Tupković E. Some aspects of depression in seniors. Medical Journal. 2010; 6(1/2):24-28

(21) Urošević J, Davidović M, Odović G, Alexopoulos GC, Mitrović Lj. Prevalence of depression in elderly persons. PONS Med J. 2010;7(4):144149 